\title{
Review
}

\section{Humor and Laughter may Influence Health. I. History and Background}

\author{
Mary Payne Bennett ${ }^{1}$ and Cecile A. Lengacher ${ }^{2}$ \\ ${ }^{1}$ Indiana State University College of Nursing, IN, USA and ${ }^{2}$ University of South Florida College of Nursing, FL, USA
}

\begin{abstract}
Articles in both the lay and professional literature have extolled the virtues of humor, many giving the impression that the health benefits of humor are well documented by the scientific and medical community. The concept that humor or laughter can be therapeutic goes back to biblical times and this belief has received varying levels of support from the scientific community at different points in its history. Current research indicates that using humor is well accepted by the public and is frequently used as a coping mechanism. However, the scientific evidence of the benefits of using humor on various health related outcomes still leaves many questions unanswered.
\end{abstract}

Keywords: Humor - Health

\section{Can Humor and Laughter Influence Health Outcomes?}

\section{History}

Using humor to decrease stress, diminish pain, improve quality of life and even attempt to improve immune functioning has recently become a popular topic in the lay and professional literature (1-4). Laughter in response to a humorous stimulus is a natural occurrence and does not require large amounts of time or money in order to implement. While therapies such as relaxation and exercise require significant time and commitment, and therapies such as herbs or massage can be expensive, use of humor can be easily implemented and cost effective. However, clinical benefits must still be documented before this therapy can be widely supported by the health care community.

Diverse literature suggests that effects of humor on various outcomes such as stress, health and immune function have been well-documented by empirical research and are therefore commonly accepted. The work of Cousins (5), Fry (6-11), Berk (12-17) or the field of Psychoneuroimmunology (PNI)

For reprints and all correspondence: Mary Payne Bennett, Indiana State University College of Nursing, IN, USA. Tel: 1-812-237-2320;

Fax: 1-812-237-8895; E-mail: mbennett2@isugw.indstate.edu is frequently cited as supporting the role of humor in healing. However, despite media claims, relatively few professional articles examine the scientific basis for these claims. There are a few studies that have examined the effects of humor or laughter on psychological outcomes, such as stress. However, there are a very limited number of studies that document the effects of laughter on physiological outcomes, and no controlled studies have been identified that document the effects of laughter on clinical health outcomes.

So what do we really know about the role of sense of humor, use of humor by patients with various illnesses, or the effects of laughter on various health related outcomes? Is use of humor an approach that we should implement in our practices and/or recommend to our patients? This is the first of the four articles that reviews, clarifies and synthesizes the professional literature concerning humor and health outcomes. This first paper presents basic background on the theoretical underpinnings concerning how the mind can affect the body, such as the effects of stress on immune functioning. Research in this area provides fundamental support for the supposition that interventions that lower stress may also help improve physiological outcomes. The second paper reports studies that document patient interest in and use of humor as a complementary therapy, and provides evidence to support that humor may be one of the more frequently used complementary therapies. The third paper describes studies that report

(C) The Author (2006). Published by Oxford University Press. All rights reserved.

The online version of this article has been published under an open access model. Users are entitled to use, reproduce, disseminate, or display the open access version of this article for non-commercial purposes provided that: the original authorship is properly and fully attributed; the Journal and Oxford University Press are attributed as the original place of publication with the correct citation details given; if an article is subsequently reproduced or disseminated not in its entirety but only in part or as a derivative work this must be clearly indicated. For commercial re-use, please contact journals.permissions@oxfordjournals.org 
the relationship between sense of humor and various health outcomes. The final paper examines either the effect of a humorous stimulus and/or effects of laughter on health outcomes. These latter two parameters are difficult to separate, since patients who are exposed to a humorous stimulus usually respond with laughter, however, not all studies separately document laughter and exposure to a humorous stimulus.

This review is based on a search of Pub-Med and PsychINFO, using the search terms humor and laughter, plus bibliographic review for older articles that may not be documented in the databases. A search using those terms produced 324 hits, from which 55 relevant articles were obtained. Only original empirical research reporting the psychological or physiological effects of humor or laughter are reported here, with the main focus on research documenting health related outcomes. Owing to small sample sizes in most studies and the limited number of available reviews, sample size was not used as a determinant to exclude certain analyses from our review. A meta-analysis was not possible owing to the use of multiple measures of sense of humor and various outcomes utilized in the studies reviewed.

\section{Definitions}

A full discourse on humor theory is beyond the scope of this review, but certain basic definitions are essential. From a psychological perspective, humor involves cognitive, emotional, behavioral, psycho-physiological and social aspects (18). The term humor can refer to a stimulus, which is intended to produce a humorous response (such as a humorous video), a mental process (perception of amusing incongruities) or a response (laughter, exhilaration). Laughter is the most common expression of humorous experience. Humor and laughter are also typically associated with a pleasant emotional state (18). For the purpose of these reviews, humor is defined as a stimulus that helps people laugh and feel happy. Laughter is a psychophysiological response to humor that involves both characteristic physiological reactions and positive psychological shifts. Sense of humor is a psychological trait that varies considerably and allows persons to respond to different types of humorous stimuli. It is necessary to differentiate between these variables, as some analyses of humor use a humor stimulus (such as a video) to determine the effect of 'humor' on an outcome, while others look specifically at the effects of laughter on these outcomes. Still others analyze various ways to measure sense of humor, in an attempt to determine whether scoring higher on a sense of humor instrument is related to various health related outcomes.

\section{Stress, Psychoneuroimmunological Reactions and Health}

\section{Theoretical Framework and Early Experiments}

What is the underlying theoretical framework that helps explain why use of a complementary therapy, such as humor, may affect health? It may be that these therapies work by reducing the effects of stress. Interest in the influence of psychological factors on susceptibility to certain disease states goes back to the times of Galen (19), when it was noted that persons who developed cancer often had a 'melancholic' personality. Since then, numerous clinicians have shared anecdotal data concerning the development of cancer or other diseases in persons with certain psychological styles, or after a stressful life event, such as bereavement (20).

Selye's work was one of the first to document the general effects of stress on the sympathetic nervous system, endocrine system and lymphatic organs (21). Further studies established that activation of the stress response could also be triggered by acute emotions, physical exertion, cold and pain (22). Later, Lazarus and Folkman (23) broadened the definition of stress from Selye's concept of 'environmental demands' to include psychological components such as appraisal and coping. While Lazarus and Folkman's theory helped to explain the moderation of stressors using coping mechanisms, it did not attempt to explain the possible consequences of these coping mechanisms in terms of physiological effects on immune functioning. The field of PNI brings all of these factors together in a testable theoretical framework. PNI started from a multifactorial model of illness, which included stress, coping and disease formation (24). This theory was further developed by Solomon (1987) to include the impact of stress on the immune system in disease formation (25). Later, the term 'psychoneuroimmunology' was coined by Ader and Cohen (26) to describe the basic phenomena of this theory: interactions between the nervous system and the immune system, and the subsequent effects of these interactions upon disease development/progression.

\section{PNI and Stress}

PNI researchers have repeatedly documented that increased stress levels can lead to changes in psychological and physiological functioning. In addition to changes in the usual stress hormones such as ACTH, cortisol, epinephrine and norepinephrine, many other messengers are influenced by exposure to stressors. Production and release of prolactin, growth hormone, insulin, glucagon, thyroid hormone and gonadotrophin can be affected by physical and emotional stress (27). Levels of neurotransmitters, neurohormones, cytokines and various cells in the immune system can also be affected by stress (28).

\section{A Neurological Approach to Laughter}

Ideally, we would be able to draw a flow chart that outlines all of the neurological processes involved in the effects of laughter on stress and immune functioning. But unfortunately, the state of the science is not to that level at this time. We really know very little about how the brain functions in response to a humorous stimulus. According to Curtis (27), speech and laughter are both uniquely human. But while there is considerable information on the neuronal representation of speech, little is known about brain mechanisms of laughter. We do have some evidence that the supplementary motor area of the 
brain is involved in this response. Curtis reports that "electrical stimulation in the anterior part of the human supplementary motor area (SMA) can elicit laughter' (29). Moreover, it has been proposed by Tanji (30) and Picard and Stick (31) that the anterior part of the SMA is part of a further development in humans to accommodate the specialized functions of speech, manual dexterity and laughter. This area might correspond to the pre-supplementary motor area, a region situated anterior to the SMA proper, recently described in non-human primates, and thought to be involved in high-level motor programming (30,31). Finally, Fried and Wilson (32) have examined putative regions in the brain using electric current that stimulates laughter. The data suggest that this is at least one anatomical location for the neurological response to humorous stimuli. However, more research is needed to determine how these neurological changes subsequently affect the physiological response to stressors, and possibly improve immune functioning.

\section{References}

1. Balick M, Lee R, The role of laughter in traditional medicine and its relevance to the clinical setting: Healing with ha! Altern Ther Health Med 2003;9:88-91.

2. Bennett H, Humor in medicine. South Med J 2003;96:1257-61.

3. MacDonald C, A chuckle a day keeps the doctor away: therapeutic humor and laughter. J Psychosoc Nurs Ment Health Serv 2004;42:18-25.

4. Weiss R, Initiative proves laughter is the best medicine. Health Prog 2002;83:54.

5. Cousins N, Anatomy of an Illness as Perceived By the Patient. Toronto: Bantam, 1979.

6. Fry W, Mirth and oxygen saturation levels of peripheral blood. Psychother and Psychosom 1971;19:76-84.

7. Fry W, The respiratory components of mirthful laughter. J Biol Psychol 1977;19:39-50.

8. Fry W, Humor, physiology, and the aging process. In Nahemov L, McCluskey-Fawcett K, McGhee P, (eds), Humor and Aging, Orlando, Florida: Academic Press, 1986, pp. 81-98.

9. Fry W, Savin W, Mirthful laughter and blood pressure. Humor: Int J Humor Res 1988;1:49-62.

10. Fry W, The physiological effects of humor, mirth, and laughter. J Am Med Assoc 1992;267:1857-8.

11. Fry W, The biology of humor. Humor: Int J Humor Res 1994;7:111-26.

12. Berk L, Tan S, Nehlsen-Cannarella S, Napier B, Lewis J, Lee J, et al, Humor associated laughter decreases cortisol and increases spontaneous lymphocyte blastogenesis. Clin Res 1988;36:435A.
13. Berk L, Tan S, Napier B, Evy W, Eustress of mirthful laughter modifies natural killer cell activity. Clin Res 1989;37:115A.

14. Berk L, Tan S, Fry W, Napier B, Lee J, Hubbard R, et al, Neuroendocrine and stress hormone changes during mirthful laughter. Am J Med Sci 1989;298:391-6.

15. Berk L, Tan S, Fry W, Eustress of Humor associated laughter modulates specific immune system components. Annals of Behavioral Medicine Supplement, Proceedings of the Society of Behavioral Medicine's 16th Annual Scientific Sessions 1993;15:S111.

16. Berk L, Tan S, Eustress of mirthful laughter modulates the immune system lmyphokine interferon-gama. Annals of Behavioral Medicine Supplement, Proceedings of the Society of Behavioral Medicine's 16th Annual Scientific Sessions 1995;17:C064.

17. Berk L, Felten D, Tan S, Bittman, Westengard J, Modulation of neuroimmune parameters during the eustress of humor-associated mirthful laughter. Altern Ther Health Med 2001;7:62-72, 74-6.

18. Martin R, Humor, laughter, and physical health: methodological issues and research findings. Psychol Bull 2001;127:504-19.

19. Chiappelli F, Prolo P, Cajulis OS, Evidence-based research in complementary and alternative medicine I: History. Evid Based Complement Alternat Med 2005;2:453-8.

20. Locke S, Kraus L, Modulation of natural killer cell activity by life stress and coping ability. In Levy S (ed), Biological Mediators of Behavior and Disease: Neoplasia. New York: Elsevier, 1982, pp. 3-28.

21. Seyle H., The general adaptation syndrome and the diseases of adaptation. J Clin Endocrinol Metab 1946;6:117-230.

22. Cannon W, Bodily Changes in Pain, Hunger, Fear and Rage. Boston: Charles T. Branford, 1946.

23. Lazarus R, Folkman S, Stress, Appraisal, and Coping. New York: Springer, 1984.

24. Engel G, Psychological Development in Health and Disease. Philadelphia: Saunders, 1962.

25. Soloman G, Psychoneuroimmunoloic approaches to research on AIDS. Ann N Y Acad Sci 1987;494:928-36.

26. Ader R, Cohen N, Conditioned immunopharmacologic responses. In Ader R (ed), Psychoneuroimmunology. New York: Academic Press, pp. 6-38.

27. Curtis G, Psychoendocrine stress response: Steroid and peptide hormones. In Stoll BA (ed), Mind and Cancer Prognosis. Chichester: John Wiley \& Sons, 1979, pp. 61-72.

28. Anderson G, Kiecolt-Glaser J, Glaser R, A biobehavioral model of cancer stress and disease course. Am Psychol 1994;49:389-404.

29. Fox PT, Ingham RJ, Ingham JC, Hirsch TB, Downs H, Martin C, et al, A PET study of the neural systems of stuttering 158. Nature 1996;382: 158-61.

30. Tanji J, New concepts of the supplementary motor area. Curr Opin Neurobiol 1996;6:782-7.

31. Picard N, Strick PL, Motor areas of the medial wall: a review of their location and functional activation. Cereb Cortex 1996;6:342-53.

32. Fried I, Wilson CL, Electric current stimulates laughter. Nature 1998; 391:650.

Received March 30, 2005; accepted December 29, 2005 


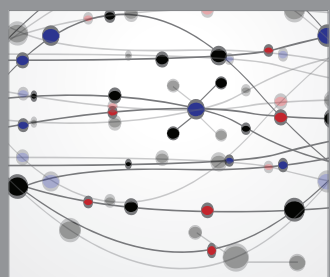

The Scientific World Journal
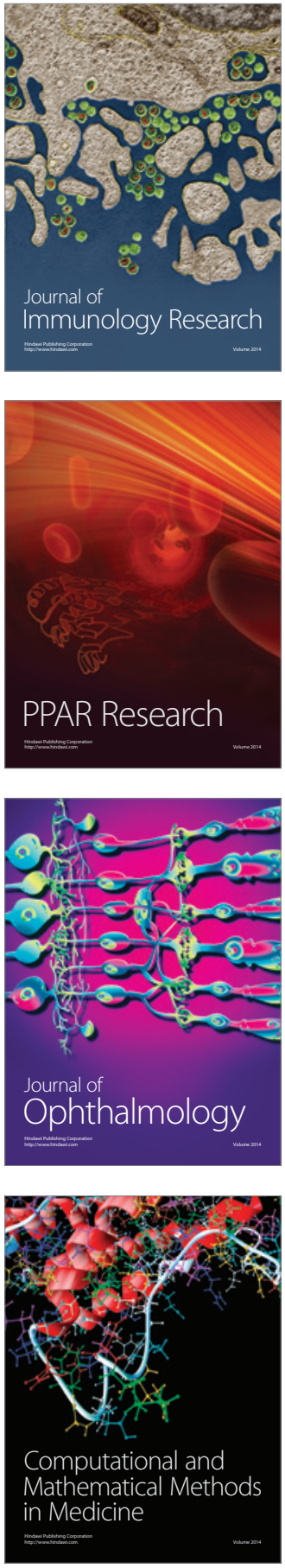

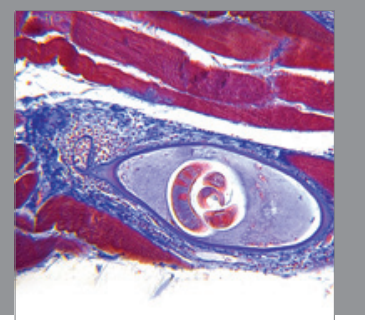

Gastroenterology

Research and Practice
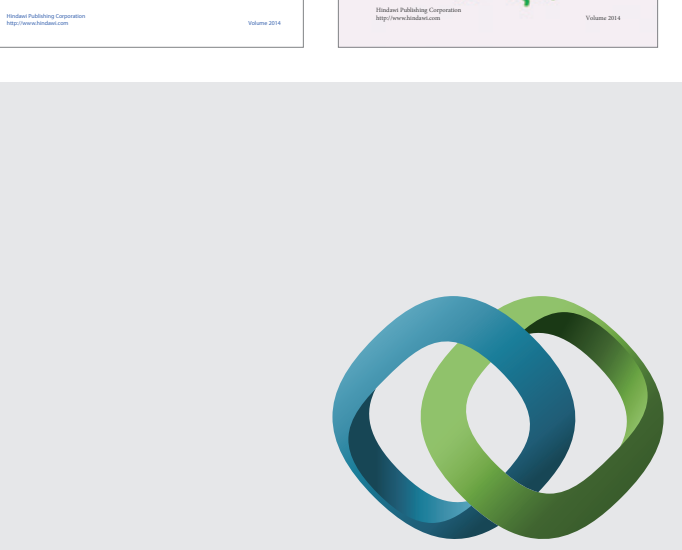

\section{Hindawi}

Submit your manuscripts at

http://www.hindawi.com
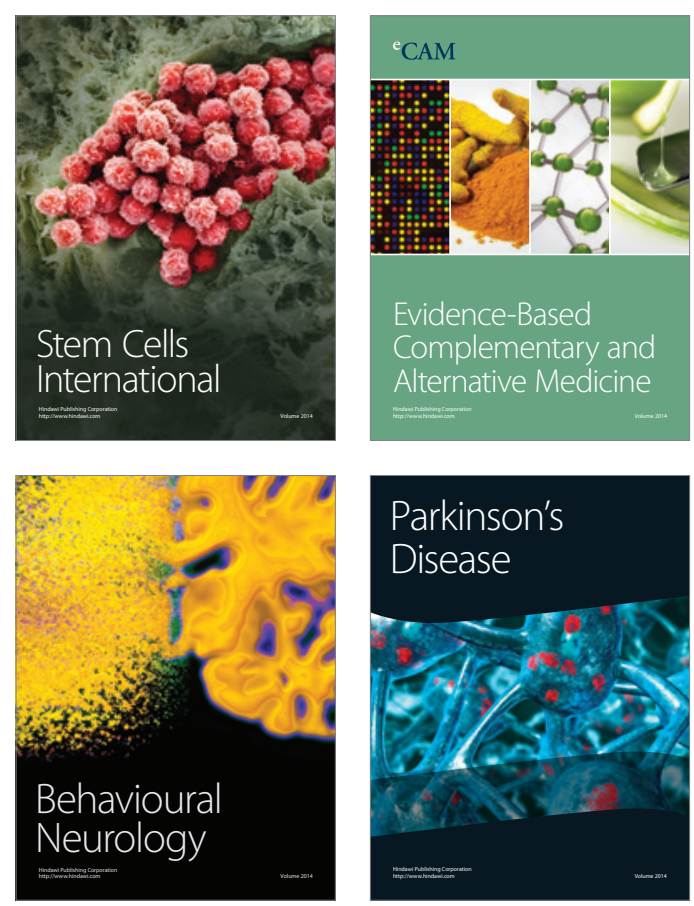

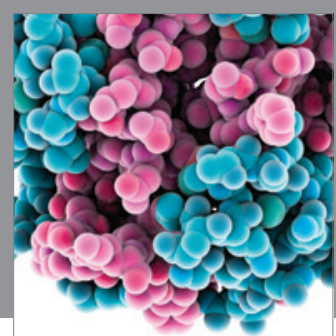

Journal of
Diabetes Research

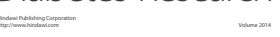

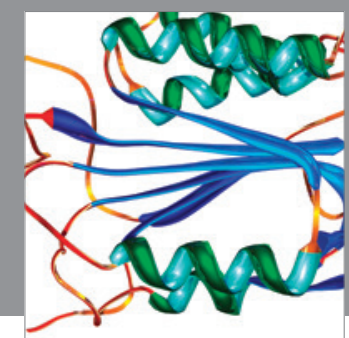

Disease Markers
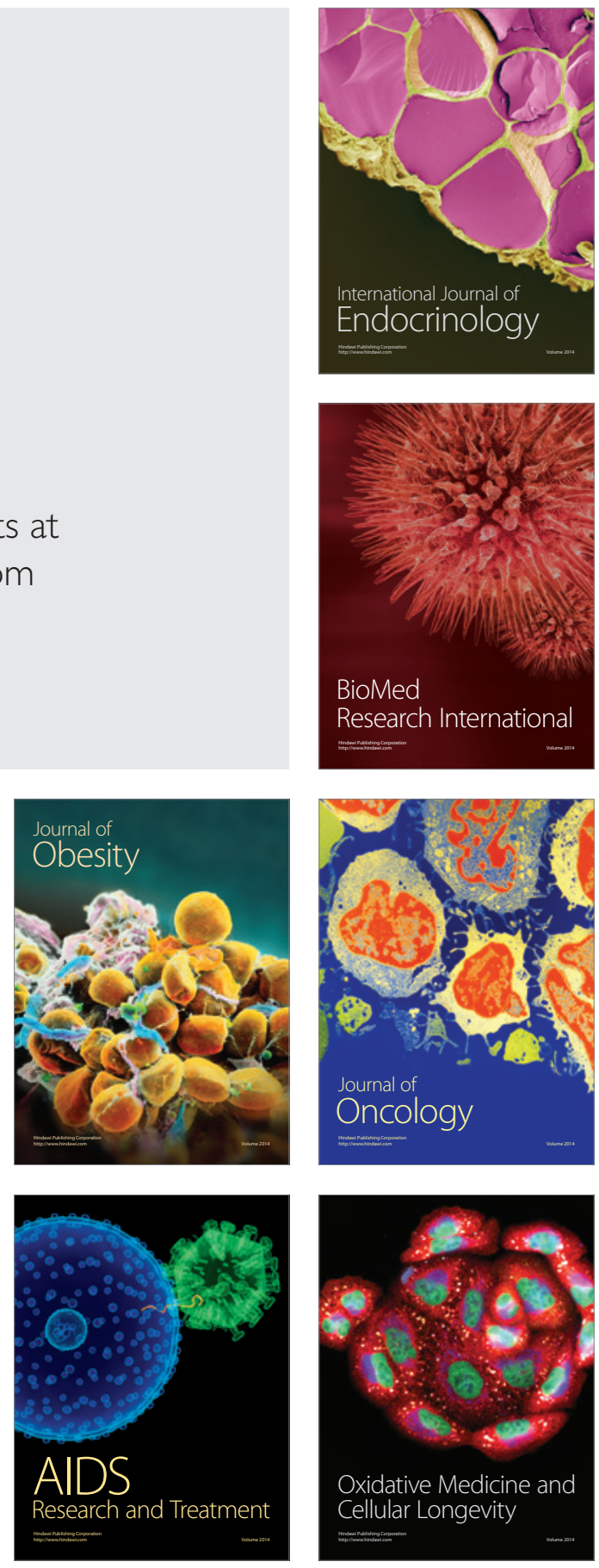